\title{
Effect of Western Culture on Indian Culture
}

\author{
Rimmy Chuchra \\ Department of ComputerScience \& Engg \\ Sri Sai College of Engg. \\ And Technology, \\ Manawala (Amritsar) \\ Punjab
}

\author{
Navreet Kaur \\ Department of ComputerScience \& Engg \\ Sri Sai College of Engg. \\ And Technology, \\ Manawala (Amritsar) \\ Punjab
}

\begin{abstract}
In the modern era, it has been observed that the greater involvement of western culture in Indian culture spoils Indian youth. The quality of love (QOL) in twenty first century Indian youth has been continuously degraded now a days because of the structure of true love in lover's relationship is not defined clearly. In this paper, authors perform a theoretical analysis on four different types of relationships viz. one-to-one, one-to-many, many-to-one, many-to-many exists in $21^{\text {st }}$ century youth correspondingly proposes two methodologies that are termed as break-up for love making and break_up after time pass. The significance to develop new methodologies is to measure the quality of true love in twenty first century youth. The motivation towards the measurement of quality of love $\left(\mathrm{QOL}_{\mathrm{O}}\right)$ is to maintain the reliability or stability in lover's relationship throughout the life. As results collected from theoretical analysis, the quality of love $\left(\mathrm{QOL}_{\mathrm{O}}\right)$ can be easily measured by studying several different parameters as an example loyalty, honesty, truthfulness, ego, satisfaction etc. After the measurement of quality of love, they will further calculate the degree of quality of love by utilizing proposed formulae. The most important or interesting parameter used to measure the degree of quality of love is to check the level of understanding between lovers where both are individual personalities.
\end{abstract}

\section{Keywords}

DQOLo (Degree of Quality of Love), Relationship status, quality of love (QOLO), love cycle, break-up, Human Behavior, opposite-sex friendships.

\section{INTRODUCTION}

LOVE [16] is an interesting topic to study across several disciplines. Fall in Love is a part of neurobiology [17] that correspondingly helps to measure several brain activities [15]. Activities may change as per growing age of humans. They may effect on people life but that only depends on the vision of the people how they consider things. They may either take the things in positive manner or may be in negative manner as discussed below with the help of an example of use of social networking websites in our daily life or media etc. The social networking websites are the hub of information exchange similarly media say the role of TV serials, is also same. Both have some positive and negative that depends on the vision of the person how they consider the impact of different tv serials like on the audience mind set as an example authors did survey on several social networking websites such as facebook, orkut twitter etc has more negative impact on people especially in the origin of opposite sex friendship. The main cause is it provides long time connectivity with beloved ones and maximum information exchange as like sharing of photos \& videos is possible. This problem may shapes into crime in future but that depends on the person mindset how they consider the things. Most of the people see different types of TV Serials in which media shows rape cases of youngsters that comes under different reality shows like savdhaan India, cord-raid, emotional ateachaar, yeh hai ashiqi etc they shows a greater negative impact on society of forceful cross-sex relationships [18]. As the maximum interference of western culture in Indian culture started spoiling of Indian youth because of the Indian youth especially the class of teanagers is affected by them that's why the number of conflicts may increase day by day because of lack of understanding between individual personalities and have no clear implifications of emotional feelings as an example how feelings of sexual attraction effect towards a friend (in case of one sided love) or towards a boyfriend? [3] As we all know, Love [16] may consider into many forms like love with family, love with friends and love with life partner [19] etc. Each form of love gives a birth of new human being who belongs to many relations simultaneously. Love [16] actually saturates our lives from birth until death, assisting in creating lasting connections with others; after all, humans are interpersonal creatures by nature they may be attracted towards each other naturally as an example any xyz person who is fall in love with someone then it will auto-reflected by his impression[8]. It is an important factor that reflects the beginning of lover's relationship. The significance to study four types of relations in lover's relationship helps to measure the real quality of love (QOLO) by considering different parameters like loyalty, honestly, truthfulness [6] etc. If these factors are already exists in someone relationship then it ultimately helps to maintain the strength of any relation [1]. Any relation may only be reliable (i.e. - continuity in lovers relationships without break-ups) if the behavior of partners is too understandable towards each other. According to the thinking of today's youth a relation will only be long life if they uses strong communication channels like mobile phones or internet for continue contact with their partners [4][7][5]etc. Moreover, by utilizing these strong communication channels with different maintenance strategies [2] the maintenance of relationships will be quite easy but it always not gives accurate results. There are some exceptions. One of the most common exception is human behavior prediction. The exact prediction of any human being is not calculated in unpredictable future [9]. It is little bit tough task for us even researcher's found number of results approximately but not accurately. Through Attitude the judgement of human understanding level may be easy [10].As different types of human behavior is judged by them by utilizing different scientific methods say by using dynamic models they already implemented Marcov Model. The benefit to use this chain is the prediction of human behavior within few seconds [12].

In this research paper, authors contributes their efforts on the theoretical analysis of different types of relationships exists in 
21 st century youth and also describes how they effect on Indian society while adopting western culture? Authors designed two algorithms for measuring the true quality of love present in 21 st century youth. These new designed methodologies named as Break_Up algorithm for love making and Break_Up algorithm after time pass. Each step of algorithm clearly defined the growth of lover's relationship from the origin The main objective of this research paper is to determine the real quality of love (QOLo) as authors considers three main parameters for the measurement of true love viz. loyalty, honesty and truthfulness etc. These certain parameters clarifies the nature of love viz. quantitative versus qualitative? Authors declared results after surveyed, if somebody relationship is hundred percent loyal with his/her partner then nothing wrong will be happen in future. As results founded, the true love in lover's relationship is constant (i.e. true love is directly proportional to loyalty) and can only be seen in very rare cases in 21 st century youth but the rate of love varies in most of the cases and that can be depend on the person character or behavior. Character is a combination of several mental characteristics and behavior. After theoretical analysis among different types of relationships. Authors concluded the absence of true love behind today's relationships. According to calculated results the existence of loyalty for live in relationship is only $10 \%$ out of $100 \%$. By utilizing this given below expression the loyalty factor can easily be formulated:

Loyalty: $=(\text { Trust }+ \text { Honesty })^{*} 100 /$ Time.

Loyalty: Level of faith.

The base of true love is only loyalty with integrity.

\section{"Quality of Love is more important than Quantity of} Love".

So need to maintain a true relationship towards his/her partner. Even authors noticed the ratio of fake relationships is going to be increases day by day and this is only due to maximum interference of western culture in Indian society. As per time passing, slowly-slowly, the enrollment of western culture helps to spoiling Indian culture actually. This can be easily discussed by considering a case study on real life example that can be discussed below:

Authors did analysis on increased rate of boyfriend-girlfriend relationship in 21ST century youth. This type of relationship is actually a part of western culture that is very common in Indian culture now a days. This involvement of western culture in Indian culture gives a new shape to Indian society. As authors surveyed on 19th century youth, people were illiterate they were less concerned about what was going outside their homes means is society rules and type of methodology followed by the system by their head of the village/town etc. Due to unawareness they faced number of problems so authors give case study especially on Punjab state people who were illiterate. For improving the level of Punjab state in education sector Government started "SARV
SIKHYA ABHIYAAN" charitable trust that cost nothing from people even facilitate them towards the awareness in education system for future. In addition, it also provides the knowledge of latest trends is going for the development of Indian nation. Previously, they did not allow their kids especially girls for going outside from the home in schools or colleges for education. But now such type of thinking is almost eliminated and their minds sets are changed now and see villager people becomes advanced now and are also interested for giving a good quality of education to their kids. That's why they send their kids to outside the village for learning. When authors considered a case of 19th century, youth were unaware about outside the world means what was going outside the home whatever their parents said they believed that's fine for them even they were not analyzed the things properly that are related to their life. They faced number of problems especially taking even a small decision in life. The reason behind this is only illiteracy correspondingly the advantage was that people were well attached with the fundamentals of culture and customs had been obeyed significantly. Most of the time they spent their time with their family so they were unable to oppose own family members and live their life peacefully. But with the changing trends towards technology (21st century) in IT sector change the vision of people as shows everything changed. As an example the development of social media or social networking websites develops a society positively provides a communication channel for message transfer/for information exchange and correspondingly having major drawback or negative point that is the origin of confidential information leakage. In general, nothing is going to be right or wrong in this world it all depends on the vision of the human being. It may be positive or negative that can only be decided by state of mind of any human being. In past, there were no more facilities in villages due to lack of resources but now a days the villager people are also enjoying the same facilities as like hyper cities people. The advancement in IT Sector fulfills the demands of resources in rural areas and most of the Villager's People are motivated especially towards education. And now they are considering an education is mandatory for their child's even for a girl kid. As per increased awareness of villager people this problem is little bit reduced but correspondingly it gives birth to one new problem that is their child's are going out of control by following western culture when go outside from the home they are continuously learning number of things from the changing environment or from their friends that may either affect positively or negatively.

\subsection{Theoratical Analysis Based On Different Types Of Relationships}

Authors did analysis on four stages involved in the beginning of any relationship that can be shown in fig.1: 


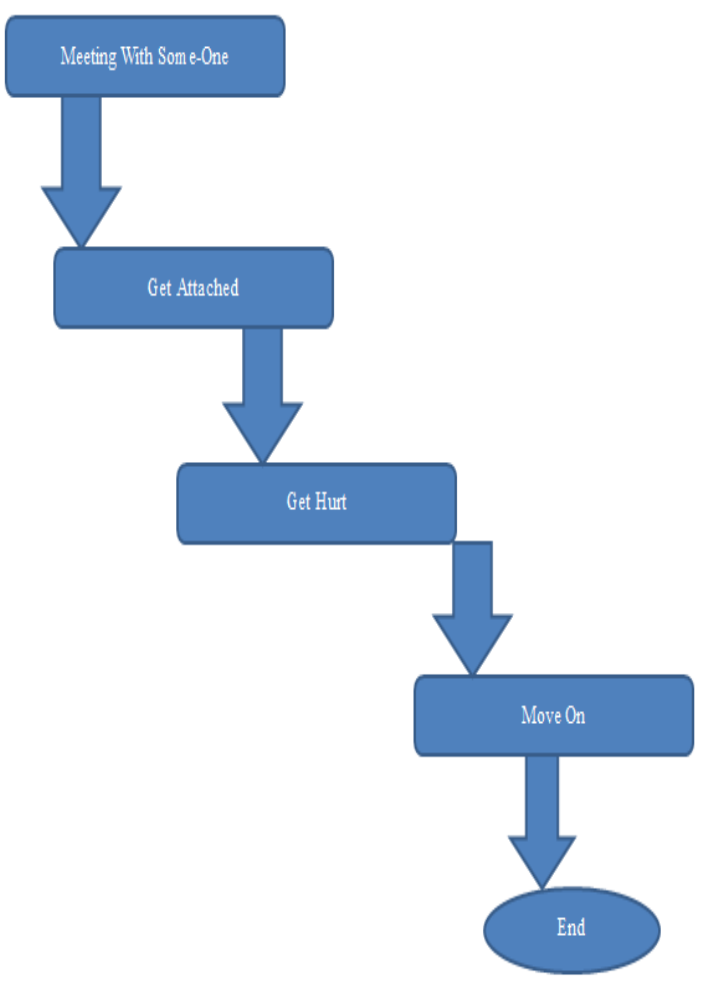

Fig.1: 4-Stages For the Beginning of Live In a Relationship.

A diagrammatical representation for love cycle in 21 st century couples who are live in relationship that can be shown in fig 2

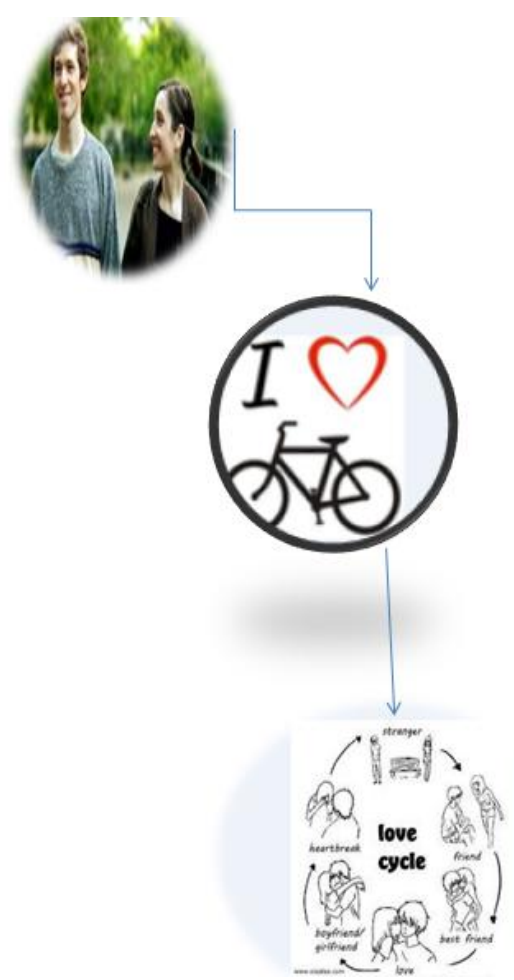

Fig.2: Steps enabled for live in a relationship.

They also discussed about four different types of relationships viz.one-to-one, one-to-many, many-to-one, many-to-many etc. exists in today's youth that can be represented below with the help of diagrams from fig. 3 to fig. 7 :
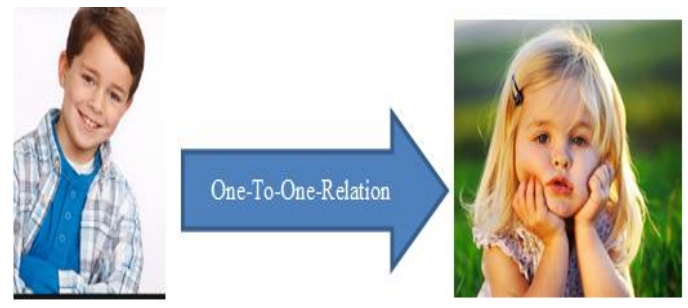

Fig.3: One-To-One Relation.

For any boy, One-to-many relation can be represented as shown in fig4:

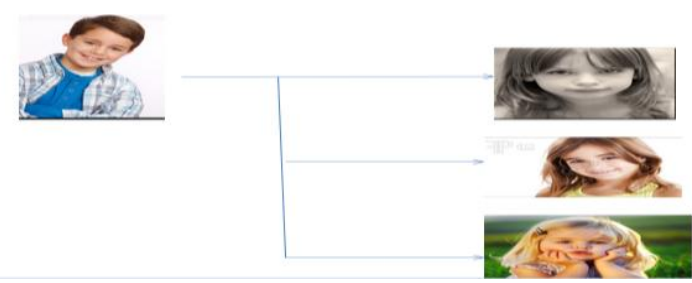

Fig.4: One-To-Many-Relation

For any Girl, One-to-many relation can be represented as shown in fig.5:

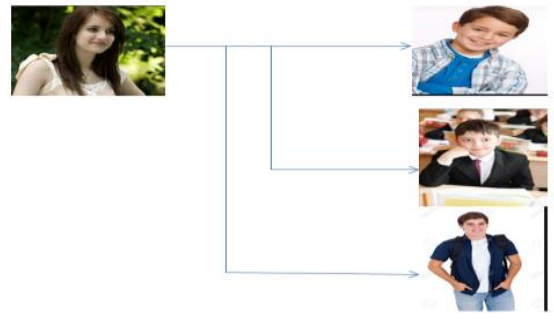

Fig.5: One-To-Many-Relation.

For any Girl, Many-to-many relation can be represented as shown in fig.6:

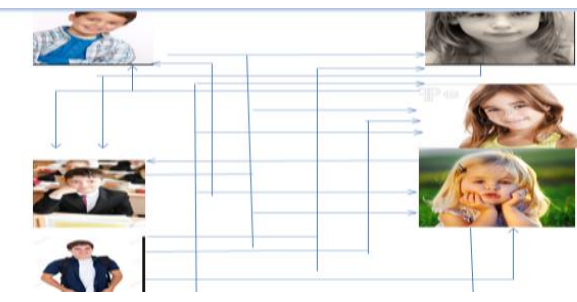

Fig.6: Many-To-Many-relation.

For any Girl, Many-to-one relation can be represented as shown in fig.7:

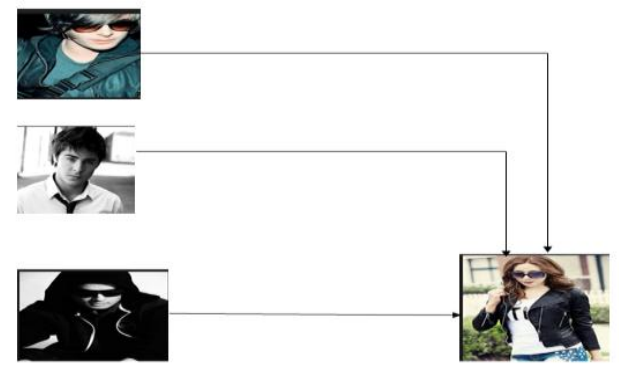

Fig.7 : Many-To-One Relation. 
As per results collected by the authors they said the management of multiple relations at a single time for a single person is too difficult because of on that time they are concentrating only on single relation and forget about others. For saving a single relation they are actually loosing many other relationships as like they cheat their parents at every step, telling lie to their friends when met with their partner etc. Even sometimes due to pre-mature stage they took wrong decisions and actions in life. For this, they paid in life for a long time. Ultimately, they will now getting out of control from their parents hand slowly-2.One day this imbalance life will may lead to that specific person dark future.

As per author point of view, nothing is good or bad in this world that only depends on the vision of the person as an example for making boy-friend/girl-friend relation is not bad that depends on the type of person as well as time but for more tighten the strength the maintenance of any relation is more important than establishment just like marriages are not so important but still the life after marriage is more important. According to nine years' experience of authors, the stability of any relation in today's youth is only based on demand basis. Demands may be of any type say related to money or related to anything as they considered a most common example of college life most of the boys make girl friends for completing their assignments and making notes near examination. They only see main three factors according to the situation viz. demand, relation and time. These are basically relative terms that show a directly proportional relationship in fig.8:

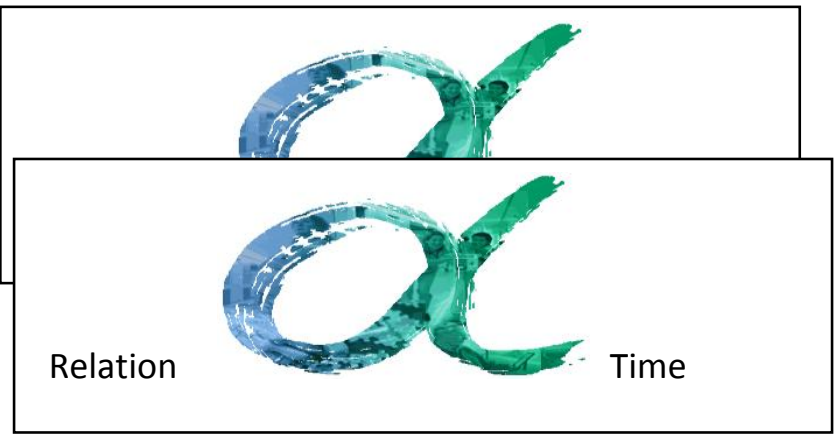

Fig.8: Relation between Demand and Time.

This expression shows the complete dependency of today's relationship. For example: if demands will be fulfilled on dedicated time then relation will going continuously in smooth manner otherwise some session breaks will definitely come in future. The graph indicates that the growth rate of true love is going to be decreases day by day that correspondingly increase the growth of fake love as shown in fig.9

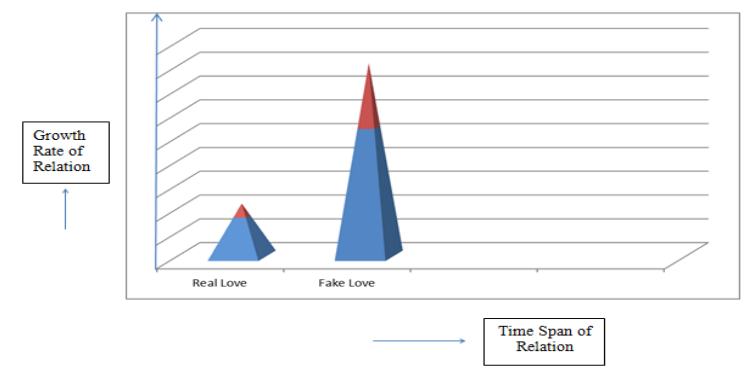

Fig.9:Graph shows the growth of True love and Fake Love.
This graph shows in future the rate of true love will going to be continuously decreased and in the end there will be no heart-to-heart connectivity for upcoming generation/XYZ generation. The main cause is the increased rate of EGO. When enters into relation then it will destroy almost everything in relation. As a true saying said by a great philosopher is:

\section{“RELATIONSHIPS NEVER DIE A NATURAL DEATH THEY WILL ONLY MURDERED BY EGO/ATTITUDE AND IGNORANCE”.}

So, the better solution is removing $\mathrm{E}$ and just GO. In this way, we can kill EGO and maintain a smooth relation. Authors advised us please do not put your ego especially in front of those people who loves you most.

\subsection{Comparison between Past and Present Relationship Status}

As per changing time and environment [13] the intimacy in relationships [11] continuously going to be changes and build a new shape with time that automatically creates a differentiation between the past and present relationships of youth. After conducted a survey they found results previously when they may face critical problems in live in relationship then they committed suicide types of things and ballah-ballah because of they were sincere enough towards each other but this thing is missing in today's youth/21st century relationship [19] if there are some problems in their relation they simply go for break-up especially enjoying with a party that is named as "Break-Up Party" as seen in Love Aj Kal Movie. The big reason for that is knowledge of lack of understanding between the partners who are committed with each other. An understanding can only occur in a relation when one person can consider partner problem as own problem and put equal efforts to solve that specific problem that can be easily shown as an example given below:

HIS Problem $=$ HER Problem $=$ Together looking for solution.

If nothing will happen like this that clearly shows existence of fake relationship. Simply both are just believe in time pass during live in a relationship and there is no guarantee or stability in their relation because of relation is only on demand basis as authors discussed above. In this way, they said this 21 st century youth signifying a new focus on the quantity rather than quality that shows the separate types of variations in variable structure of relationship.

\section{RESEARCH DESIGN}

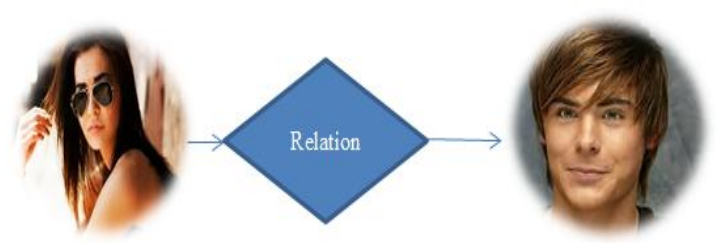

Fig.10: Mapping of boy \& girl: Define their Relationship.

\section{PROPOSED PROCEDURES}

Parent Algorithm: - Steps

3.1 Relation Building.

3.2 Relation Repair. 
3.3 Relation Replacement.

3.4 Relation Break_Up.

(3.1) Best_Friend_Relation_Building (Initialize Entity

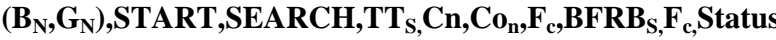
)

Step-1) Initialize Entity $(B, G):=C_{n} A_{N D ~} C_{n}$ : $=$ TRUE.

Step-2) As $\mathrm{C}_{\mathrm{IS}_{-}} \mathrm{S}_{\mathrm{TA}}:=\mathrm{S}_{\mathrm{T}}$ THEN $\mathrm{S}_{\mathrm{E}}$ FOR $\mathrm{F}_{\mathrm{C}}$.

Step-3) CHECK_TYPE_OF_FRIEND

$\left(\mathrm{B}, \mathrm{C}_{\mathrm{T}}, \mathrm{H}_{\mathrm{S}}, \mathrm{STATUS} *(\mathrm{R}, \mathrm{W}, \mathrm{NR})\right)$

A) CALCULATE Behavior of Friend at $\mathrm{C}_{\mathrm{T}}$.

IF (B: = TRUE AND $\mathrm{C}_{\mathrm{T}}=$ TRUE $)$

\{

$\mathrm{H}_{\mathrm{S}}:=\mathrm{READY}$.

ELSE IF (B: $=$ FALSE AND $\mathrm{C}_{\mathrm{T}}=$ TRUE $)$

\{

$\mathrm{H}_{\mathrm{S}}:=$ WAITING

\}

ELSE

\{

NO RESPONSE.

\}

Step 4) WHEN $\mathrm{TT}_{\mathrm{S}}$ : = TRUE WITH $\mathrm{F}_{\mathrm{C}}$ THEN DETERMINE $\mathrm{B}_{\mathrm{F} .}$

Table 1. Nomenclature for Best Friend Relation building.

\begin{tabular}{|c|c|}
\hline $\mathrm{B}_{\mathrm{N}}$ & Boy_Name \\
\hline $\mathrm{G}_{\mathrm{N}}$ & Girl_Name \\
\hline $\mathrm{S}_{\mathrm{T}}$ & Start \\
\hline $\mathrm{S}_{\mathrm{E}}$ & Search \\
\hline $\mathrm{TT}_{\mathrm{S}}$ & College_Name \\
\hline $\mathrm{C}_{\mathrm{N}}$ & Course_Name \\
\hline $\mathrm{CO}_{\mathrm{N}}$ & Friend_Circle \\
\hline $\mathrm{F}_{\mathrm{C}}$ & Status \\
\hline $\mathrm{S}_{\mathrm{TA}}$ & Critical_Time \\
\hline BFRBS & Help_Status \\
\hline $\mathrm{CT}$ & Behavior \\
\hline $\mathrm{HS}$ & Status(Ready,Waiting,No Response $)$ \\
\hline $\mathrm{S}_{\mathrm{TA}}(\mathrm{R}, \mathrm{W}, \mathrm{NR})$ & Belation_Bulding_Status \\
\hline $\mathrm{B}$ & Criend \\
\hline
\end{tabular}

$\operatorname{IF}\left(\mathrm{TT}_{\mathrm{S}}>=\operatorname{ENTITY}\left(\mathrm{B}_{\mathrm{N}}, \mathrm{G}_{\mathrm{N}}\right)\right.$ from $\left.\mathrm{F}_{\mathrm{C}}\right)$

\{

$\mathrm{BFRB}_{\mathrm{S}}=$ TRUE.

\}
ELSE

\{

$\mathrm{BFRB}_{\mathrm{S}}=\mathrm{FALSE}$.

\}

Step 5) END.

(3.2) Best_Friend_Relation_Repairing $\left(\mathrm{C}_{\mathrm{O}}, \quad \mathbf{T S}_{\mathrm{S}}\right.$, RR*,CF,S,B)

Step-1)Call Best_Friend_Relation_Building_Algorithm and REPEAT STEP FROM 1 TO 4.

Step-2) IF(C C $_{\mathrm{O}_{-}}$IN_RELATION:= TRUE AND TS $\left.\mathrm{S}_{\mathrm{S}}=\mathrm{NIL}\right)$

\{

THEN ONLY BFRB $:=$ RR$^{*}$.

\}

ELSE

\{

DEMAND FOR S FROM CF

Step-3) $\operatorname{IF}(S=100 \%)$

\{

Status_of_RR* $=$ TRUE.

ELSE

\{

Status_of_RR* $=$ FALSE.

Step-4) HENCE STATUS_OF_RELATION= BREAK.

Table 2. Nomenclature for Best Friend Relation Repairing.

\begin{tabular}{|c|c|}
\hline $\mathrm{C}_{\mathrm{O}}$ & Conflicts Occur \\
\hline $\mathrm{TS}_{\mathrm{S}}$ & Time Spending Status \\
\hline $\mathrm{RR}^{*}$ & Relation Repairing \\
\hline $\mathrm{CF}$ & Close Friends \\
\hline $\mathrm{S}$ & Support \\
\hline $\mathrm{B}$ & Break \\
\hline
\end{tabular}

(3.3) Best_Friend_Relation_Replacement $\left(\mathbf{U}_{\mathrm{L},}, \mathbf{M}_{\mathrm{L}}, \mathbf{F}_{\mathbf{S}}, \mathbf{B}_{\mathrm{UP}} \mathbf{C S}\right.$ ')

Step-1) CALL Best_Friend_Relation_Repairing_Algorithm and Repeat Step 1 and 2.

Step-2) $\operatorname{IF}\left(\mathrm{M}_{\mathrm{L}}>=100 \%\right.$ AND $\left.\mathrm{U}_{\mathrm{L}}=0 \%\right)$

\{

THEN NEEDS $F_{S}$ 
ELSE IF(F $F_{S} !=$ NIL $)$

THEN REPEAT STEP 1

\}

ELSE

$$
\{
$$$$
\mathrm{CS}^{\prime}=\mathrm{B}_{\mathrm{UP}}
$$

Step-4) START RANDOM SEARCH FOR NEW FRIEND (LIST,SS)

IF (LIST!=NULL)

\{

THEN SEARC $\quad\}$

ELSE

SEARCH FOR OTHER ALTERNATIVES TO AVOID FIGHT

\}

H START

\}

$\mathrm{IF}(\mathrm{SS}=\mathrm{TRUE})$

THEN FRIEND RELACE

\}

ELSE

\{

MOVE TO IF PORTION OF STEP 4.

Step-5) END.

Table 3. Nomenclature for Best Friend Relation Replacement.

\begin{tabular}{|c|c|}
\hline UL & Understanding Level \\
\hline ML & Misunderstanding Level \\
\hline FS & Friend Support \\
\hline BUP & Break_Up \\
\hline CS' & Current_Status \\
\hline SS & Search Successful \\
\hline
\end{tabular}

(3.4) CURRENT STATUS OF RELATIONSHIP:

[3.4.1] Break-Up Algorithm For Love Making (Initialize $\left.\mathbf{B}, \mathbf{G}_{\mathbf{L}} \mathbf{B}_{\mathrm{L}}, \mathbf{G}_{\mathrm{L}}, \mathbf{R}_{\mathrm{S}}, \mathbf{E T S}_{\mathrm{S}}, \mathbf{A T S}_{\mathrm{S}}\right)$

Input: $\mathrm{B}$ and $\mathrm{G}$ are the two entities described for given time $\mathrm{T}$, we have to make an algorithm for breakup and store the status of relation in variable $R_{S}$.
Output: $R_{S}=$ FALSE (Break-Up Successful).

$$
\mathrm{R}_{\mathrm{S}}=\text { TRUE (Break-Up Un-Successful). }
$$

Step-1) IF $\left(\right.$ ETS $\left._{\mathrm{S}}<=\mathrm{ATS}_{\mathrm{S}}\right)$

CURRENT_STATUS: = FIGHT that Results IGNORANCE in Relation.

Step-2) SWITCH(CH)

Case 1: For B, CURRENT_STATUS $\left(\mathrm{B}_{\mathrm{L}}:=\mathrm{K}_{\mathrm{G}}-\mathrm{G}_{\mathrm{L}}\right)$.

Case 2: For G, CURRENT_STATUS $\left(\mathrm{G}_{\mathrm{L}}:=\mathrm{K}_{\mathrm{B}}-\mathrm{B}_{\mathrm{L}}\right)$.

Step-3) $\mathrm{R}_{\mathrm{S}}=$ SINGLE.

Step-4) MOVE TO PAST.

Step-5) END OF THE RELATION.

Table 4. Nomenclature for Break_Up for Love Making.

\begin{tabular}{|c|c|}
\hline$B$ & Boy \\
\hline$G$ & Girl \\
\hline$B^{*}$ & Boy is Already Committed/Boy Status = DOUBLE \\
\hline$G^{*}$ & Girl is Already Committed/Girl Status = DOUBLE \\
\hline$B_{d}$ & Boy Life \\
\hline$G_{4}$ & Girl Life \\
\hline$R_{S}$ & Relationship Status \\
\hline$R_{S^{*}}$ & Multiple Relation Status \\
\hline$E T s$ & Expected Time Status \\
\hline$A T S_{S}$ & Actual Time Spending Status \\
\hline $\mathrm{K}_{\mathrm{G}}$ & Known Girls \\
\hline $\mathrm{K}_{\mathrm{B}}$ & Known Boys \\
\hline
\end{tabular}

[3.4.2] Break-Up Algorithm After Time Pass (Initialize $\mathbf{B}, \mathbf{G}, \mathbf{B}_{\mathrm{L}}, \mathbf{G}_{\mathrm{L}}, \mathbf{R}_{\mathrm{S}}, \mathbf{T S}_{\mathrm{S}}$, Current_Status,

Input: $\mathrm{B}$ and $\mathrm{G}$ are the two entities described for given time $\mathrm{T}$, we have to make an algorithm for breakup and store the status of relation in variable $R_{S}$.

Output: $R_{S}=$ FALSE (Break-Up Successful).

$$
\mathrm{R}_{\mathrm{S}}=\text { TRUE (Break-Up Un-Successful). }
$$

Step-1) IF $\left(\mathrm{ETS}_{\mathrm{S}}<=\mathrm{ATS}_{\mathrm{S}}\right)$

CURRENT_STATUS: = FIGHT that Results IGNORANCE in Relation.

$$
\text { \} }
$$

ELSE

Looking for the other alternatives for Time Pass.

$$
\}
$$

Step-2) APPLY RANDOM SEARCH (VALUE, LIST, STATUS)

$$
\text { IF (LIST: = NULL) }
$$


STATUS $=$ SINGLE.

\}

ELSE

\section{\{}

Pointer indicates to first value of list with specified Location THAT INDICATES THE CURRENT STATUS IS = DOUBLE

\}

\section{Step-3) APPLY ALGORITHM FOR} CHECK_TYPE_OF_CHARACTER_ENTITY $\left(B^{*}, \mathrm{G}^{*}, \mathrm{R}_{\mathrm{S}^{*}}\right)$

Where $B^{*}, G^{*}$ shows already Comitted_Relation for any boy or girl.

And $\mathrm{R}_{\mathrm{S}^{*}}$ shows Multiple Relations.

REPEAT STEP 2 WETHER SEARCH IS NOT COMPLETED.

Step-4) SWITCH (CH)

Case 1: For B, CURRENT_STATUS $\left(\mathrm{B}_{\mathrm{L}}:=\mathrm{K}_{\mathrm{G}}+\mathrm{G}_{\mathrm{L}}\right)$.

Case 2: For G, CURRENT_STATUS $\left(\mathrm{G}_{\mathrm{L}}:=\mathrm{K}_{\mathrm{B}}+\mathrm{B}_{\mathrm{L}}\right)$.

Step-5) $R_{S}=R_{S^{*}}$. // Belongs to High Society that ultimately Shows a Status Symbol.

Step-6) MOVE TO BRIGHT OR DARK FUTURE THAT DEPENDS ON CERTAIN TIME AND CONDITIONS.

Step-7) IF (SITUATIONS: = FAVOURABLE) //if

(Situations! =0)

\{

RELATIONSHIP_STATUS=CONTINUE.

\}

ELSE

\{

OTHERWISE RELATIONSHIP_STATUS= AGAIN_SINGLE.

// Finally Break_Up.

\}

Step-8) MOVE TO PAST.

Step-9) END OF THE RELATION.
Table 5:Break_Up Algorithm After Time_Pass.

\begin{tabular}{|c|c|}
\hline$B$ & Boy \\
\hline$G$ & Girl \\
\hline$B^{*}$ & Boy is Already Committed Boy Status = DOUBLE \\
\hline$G^{*}$ & Girl is Already Committed Girl Status = DOUBLE \\
\hline$B_{w}$ & Boy Life \\
\hline$G$ & Girl Life \\
\hline$R_{S}$ & Relationship Status \\
\hline$R_{S^{*}}$ & Multiple Relation Status \\
\hline$E T_{s}$ & Expected Time Status \\
\hline$A S_{S}$ & Actual Time Spending Status \\
\hline $\mathrm{K}_{\mathrm{G}}$ & Knorn Girls \\
\hline $\mathrm{K}_{\mathrm{B}}$ & Knorn Boys \\
\hline
\end{tabular}

\section{FLOW CHART FOR BREAK_UP}
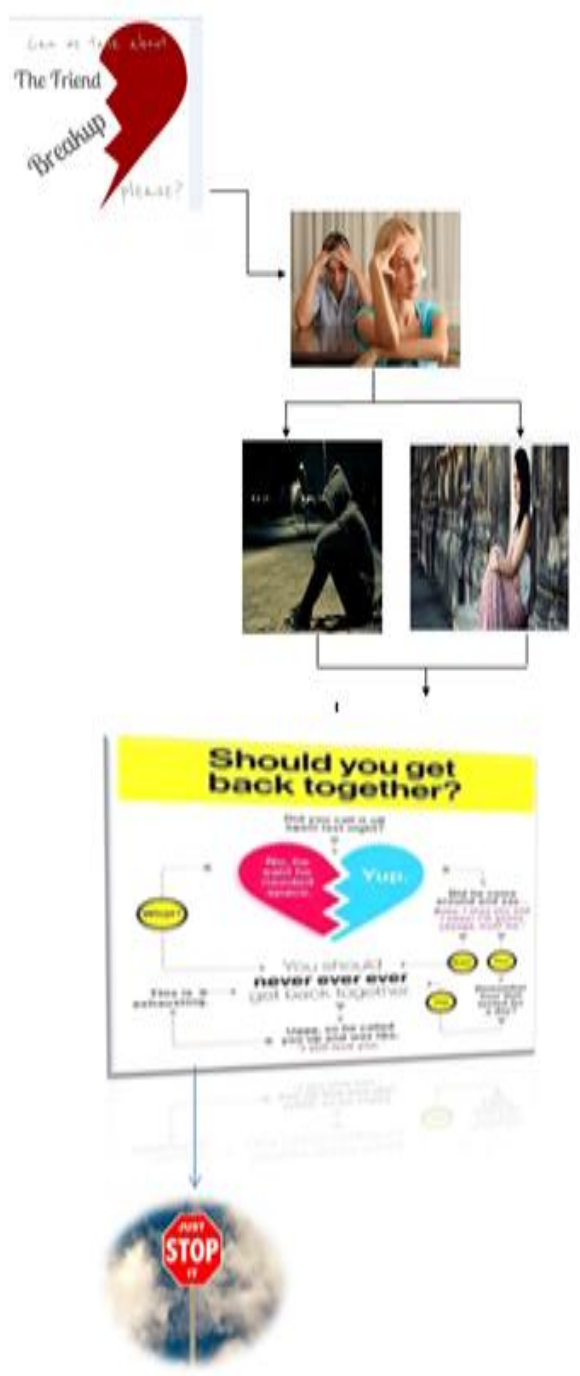

Fig.11: Steps enabled for making Lover's Relationship. 


\section{CONCLUSIONS}

Different types of relationships of lovers are reviewed and analyzed in this paper. The major benefit to designed algorithms at different steps is to check the present status of today's youth relationships that in future may use to detect the reliability/stability in lover's relationship. Authors considered some certain parameters for measuring the rate of true love gradients. The three main factors are viz. honesty; truthfulness and loyalty etc were considered by the authors. The results collected during theoretical analysis showed degradation of quality of love $\left(\mathrm{QOL}_{\mathrm{o}}\right)$ in $21^{\text {st }}$ century youth just because of time and demand basis relationships. By utilizing above discussed formulae the loyalty among any true lover's relations can be easily measured. In this way, authors contributed their efforts for the measurement of true love and the ultimate objective of authors is to enhance the quality of live by enhancing quality of love.

\section{FUTURE SCOPE}

In future, the management of different types of relationships at a single time especially in the case of mobile call will be little bit tough for future "XYZ" Generation. Extra-pairing in relationships may increase the level of cheating between the partners. Authors are assuming this upcoming generation named "XYZ generation" will try to manage/handle multiple relationships simultaneously by considering different parameters that leads to give more appropriate results. But there is one exception it is little bit tough to predict any person behavior in this unpredictable future.

\section{REFERENCES}

[1] Rooma Kapoor and Shifali Srivastva, March 2014. A Study on Quality of Work Life: Key Elements and its Implifications,,IOSR Journal of Business and Management(IOSR-JBM).

[2] Laura Stafford and Daniel J.Canary, An Inductive Analysis of Relational Maintenance Strategies: Comparisons among Lovers, Relatives, Friends and Others, Communication Research Report.

[3] Gabriela Armenta,2012.Identifying Sexual Interaction in Platonic Cross-Sex Relationships and its Effects on Friendships., Information Literacy Committee.

[4] Melissa Hope Kauffman, Aug 2008.Relational Maintenance in Long Distance Dating Relationships: Staying Close - Thesis.

[5] Alana M.Chavez and Laura K.Guerrero, Oct 2005. Relational Maintenance in Cross Sex Friendships Characterized by different types of romantic intent: An Exploratory Study", Western Journal of Communication.

[6] Manuela Thomae, Janet Fink, Martina Klett-Davies and Jacqui Gabb, Feb 2013.Enduring Love? Couple Relationships in the $21^{\text {st }}$ Century-Survey Findings an Interium Report.
[7] Brooks Aylor and Marianne Dainton, Patterns of Communication channel use in maintenance of LongDistance Relationships, Communication Research Reports.

[8] Proff. Mahesh Kumar and Sandeep Dang Sept 2014. Handwriting analysis of human behavior based on neural network, International Journal of Advanced Research in Computer Science and Software Engg.

[9] Philip Gendall and Judith Holdershaw, 2008.Understanding and Predicting Human Behavior.

[10] Gary A.Cziko 1989. Unpredictability and Indeterminism in Human Behavior: Arguments and Implications for Educational Research, American Educational Research Association.

[11] Val Gillies, june 2003.Family and Intimate Relationships: A Review of the Sociological Researc Families and Social Capital ESRC Research Group.

[12] Andrew Liu and Alex Pentland, 1999, Modeling and Prediction of Human behavior.

[13] Linda Steg and Charles Vlek, 2007. Human behavior and Environmental Sustainability: Problems, Deriving Forces and Research Topics Journal of Social Sciences.

[14] N.D.C Duncan and R.I.M Dunbar, 1997. Human Conservation Behavior, University of Liver Pool, England.

[15] M.Chapman, 2011.Love:- A Biological, Psychological and Philosophical Study, University of Rhode.

[16] ERICA OWENS, 2006. The Sociology of Love, Courtship and Dating West Virginia University.

[17] Anders Sandberg and Julian Savulescu, 2008.Neuroenhancement of Love and Marriage: The Chemicals between Us, Neuroethics, Springer.

[18] David Finkelhor and Denise A.Hines, 2007.Statutory Sex crime relationships and Juveniles and adults: - A Review of Social Scientific Research, Aggression and Violent behavior, ELSEVIER.

[19] Lydia Kathleen Merriam-Pigg, 2012.Love and Friends: Understanding Friends with benefits Relationships and Those Involved - Master's Thesis.

[20] https://www.google.co.in/search?hl=en\&site=imghp\&tb $\mathrm{m}=\mathrm{isch} \&$ source $=\mathrm{hp} \& \mathrm{biw}=1366 \& \mathrm{bih}=667 \& \mathrm{q}=\mathrm{BREAKU}$ P+IMAGES\&oq=BREAKUP+IMAGES\&gs_l=img.3..01 10.861.5758.0.8379.18.16.2.0.0.0.238.2162.0j13j1.14.0.e kpsrh...0...1.1.64.img..3.15.2030.1R86i1vrfI\#hl=en\&tbm $=$ isch \&q $=$ LOVE+CYCLE+IMAGES\&imgrc $=a u F w C 1 H$ v14edgM\%253A\%3BOLSJgjs2ybVCtM\%3Bhttp\%253A $\% 252 \mathrm{~F} \% 252 \mathrm{Fwww}$.bhmpics.com\%252Fdownload\%252 Flove_cyclewide.jpg\%3Bhttp $\% 253 \mathrm{~A} \% 252 \mathrm{~F} \% 252 \mathrm{Fwww}$ .bhmpics.com\%252Fview-love_cyclewide.html\%3B1920\%3B1200. 